\title{
Strange bedfellows: on Pritchard's disjunctivist hinge epistemology
}

\section{Annalisa Coliva $^{1}$ (D)}

Received: 4 March 2018 / Accepted: 30 November 2018

(c) Springer Nature B.V. 2018

\begin{abstract}
The paper discusses some themes in Duncan Pritchard's last book, Epistemic Angst. Radical Skepticism and the Groundlessness of Our Believing. It considers it in relation to other forms of Wittgenstein-inspired hinge-epistemology. It focuses, in particular, on the proposed treatment of Closure in relation to entailments containing hinges, the treatment of Underdetermination-based skeptical paradox and the avail to disjunctivism to respond to the latter. It argues that, although bold and thought-provoking, the mix of hinge epistemology and disjunctivism Pritchard proposes is not motivated.
\end{abstract}

Keywords Hinge epistemology · Disjunctivism · Closure ·

Underdetermination-based skepticism $\cdot$ Perception $\cdot$ Pritchard

\section{Introduction}

In this paper I propose a close examination of some prominent themes in Duncan Pritchard's Epistemic Angst (2016). Pritchard's dialectical setup is familiar to connoisseurs of hinge epistemology. ${ }^{1}$ For he contends that skepticism should be understood as a paradox, which, starting with prima facie acceptable premises, leads to the unacceptable conclusion that we do not possess knowledge of ordinary empirical propositions about mid-size physical objects in our surroundings. Moreover, Pritchard thinks that the paradox in fact comes in two distinct forms, which he calls the "Closure-based para-

\footnotetext{
1 Early examples of it are Wright (1985, 2004), Strawson (1985), Williams (1991). More recent ones are Coliva (2015) and the papers contained in Coliva and Moyal-Sharrock (2016). It is heterodox because disjunctivism is usually considered a development of Moorean rather than Wittgensteinian views, and more in keeping with an externalist rather than an internalist epistemology.
}

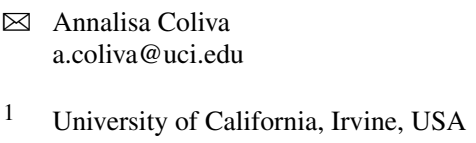


dox" and the "Underdetermination-based paradox". ${ }^{2}$ He thinks that these paradoxes put pressure on our notion of knowledge, rather than that of warrant or justification, despite what other hinge epistemologists have maintained. ${ }^{3}$ Yet, he rightly notices that the kind of knowledge targeted by these paradoxes is one that entails having rationally grounded or supported belief. Hence, that it is a notion of knowledge, which, like any epistemically internalist notion, does not sever the connection between its obtaining and its accessibility to a subject. Like other hinge epistemologists, ${ }^{4}$ Pritchard notices that crudely externalist responses are impotent vis-à-vis either form of skeptical paradox. For either they simply do not address the internalist notion of knowledge that gives rise to them; or else, they must be revisionary of the idea, which Pritchard justly sees as ingrained in our common linguistic and epistemic practices, that knowledge and having rational support for what one in fact knows can, and often do obtain together. Finally, like several other hinge epistemologists, Pritchard favors an "undercutting" anti-skeptical strategy over an "overriding" one. That is, he aims to show that the relevant skeptical paradoxes are in fact illusory (cf. p. 16), rather than real but based on notions that, once better understood and therefore revised, will not give rise to them (ibid.).

The main elements of novelty in Pritchard's version of hinge epistemology are his defense of the Closure Principle and his claim that there is nothing in Wittgenstein's On Certainty (1969) that could speak to the Underdetermination-based version of the skeptical paradox. This shortcoming, in its turn, motivates Pritchard's third main innovative move: the endorsement of epistemological disjunctivism. For, according to him, while Wittgenstein's views, once suitably developed, can take care of Closurebased skepticism, epistemological disjunctivism is called for to address the other form of the paradox. Finally, claims Pritchard, once these two paradoxes are solved in the ways proposed, it could actually be shown that, far from being in stark contrast, as most epistemologists would have it, hinge epistemology and disjunctivism can in fact lend support to each other. For, on the one hand, the Wittgensteinian strand shows the locality of epistemic evaluation and therefore sets the boundaries within which the factive rational support for our beliefs disjunctivists hold we have can in fact obtain. On the other hand, disjunctivism supplements hinge epistemology by providing it with the means to deal with Underdetermination-based skepticism.

\footnotetext{
2 Pritchard's two paradoxes are roughly equivalent to the Cartesian and the Humean paradoxes highlighted by Wright $(1985,2004)$. Pritchard argues that the two paradoxes significantly differ and that they call for rather distinct solutions. Wright, in contrast, contends that despite their differences they depend on a common lacuna in the skeptical reasoning and hence call for a unified solution. The lacuna consists in not seeing that a lack of evidential justification for the denial of radically skeptical hypotheses, such as the dreaming or the BIV one, or for heavyweight assumptions, such as "There is an external world" or "Our senses are mostly reliable", does not necessarily entail that either that denial or the relevant assumptions are not made rationally. Wright labors to show that they are because we have a rational entitlement-that is, a non-evidential warrant-for them. While I concur with Wright's diagnosis of the common lacuna motivating these forms of skepticism, in my own work I have claimed that both paradoxes proceed by assuming rightly (contra Wright) that there are only evidential justifications, but by concluding — mistakenly—that lack of justification is tantamount to lack of rationality. By contrast, I have claimed that, even if unjustified and unjustifiable, the relevant assumptions are still rational, since epistemic rationality extends to the assumptions, which make the acquisition of epistemic (evidential) justifications possible in the first place.

3 See Wright $(1985,2004)$.

4 See Wright (2004, pp. 209-211) and Coliva (2015, pp. 33-43, infra).
} 
In the remainder of this paper, I will focus on these three main aspects of Pritchard's intriguing proposal.

\section{Closure}

It is a well-known consequence of Wittgenstein's epistemology that it gives rise to what seems, at least prima facie, a denial of the Closure principle for knowledge and other epistemic operators such as evidential warrant or justification. For, given the locality of reasons, we can know (or justifiably believe), according to Wittgenstein, ordinary empirical propositions about mid-size objects in our surroundings, but we cannot know the "heavy-weight" implications of those propositions, such as "I am not a BIV" or "There is an external world", on which the very possibility of knowing ordinary empirical propositions depends. Closer to Wittgenstein's own terms, we can know, for instance, the age of a given fossil, but we cannot thereby know that the Earth has been existing for a very long time. Presumably, to gain the latter piece of knowledge, we would run something like the following argument:

(I) This fossil is 10 million years old

(II) If this fossil is 10 million years old, the Earth has existed for a very long time

(III) The Earth has existed for a very long time.

Yet, any justification we have for (I) - such as the evidence provided by radiocarbon dating - depends on taking (III) for granted. If (III) were not in place, if we thought, for instance, that the Earth had just come into existence 5 min ago replete with all fossils and everything else currently on it, we would still have the relevant evidence- - the radiocarbon dating - but no justification for (I). According to Wittgenstein, whenever we face this kind of epistemic dependence, we ought to recognize that (III) is a "hinge" (OC 341-343, cf. 105) — a necessary assumption — that needs to stay put for us to have a justification for ordinary empirical propositions like (I). If so, then, an argument like the previous one, which aimed at giving us a justification for (III), would be ultimately question begging, since it is necessary to take for granted its conclusion in order to have a justification for its premise(s) in the first place. Furthermore, for Wittgenstein, hinges are not like ordinary empirical propositions, and are in fact similar to rules. Hence, they are not suited to be the content of a propositional attitude like belief, which is, according to most, necessary for knowledge. Thus, while we may have justification or even knowledge of (I), and despite the fact that (I) entails (III), we do not have either justification for, or knowledge of (III).

Now, several hinge epistemologists are prepared to face the situation, offering considerations to minimize the allegedly devastating effects of such an admission. Some, like Wright (2004, pp. 177-178), for instance, are willing to grant that Closure does not fail for other epistemic notions in the vicinity, like rational entitlement. ${ }^{5}$ Others point

\footnotetext{
5 Wright (2012, pp. 232-235) represents a considerable change of mind with respect to Wright (2004). For Wright actually endorses the view that Closure does not fail for evidential warrant and that we can therefore augment the initial rational support we have for "There is an external world", which is merely a kind of non-evidential warrant, going through a Moore-style argument, starting with the evidentially warranted premise that here is one's hand.
} 
out that it would fail, for principled reasons, only when the consequent of the conditional is a heavy-weight implication, but not when it is any other ordinary empirical proposition. ${ }^{6}$ Hence, Closure holds, but it does not hold unrestrictedly. Yet, its limited failure would be compatible with the retention of that very principle in all those cases in which we do in fact need it in order to explain how we can extend our knowledge (or justified belief) from one ordinary empirical proposition to the consequent of a known entailment, which has the former proposition as its antecedent. ${ }^{7}$

Pritchard, in contrast, wants to maintain the unrestricted validity of the Closure principle and yet, with Wittgenstein and several hinge epistemologists, he does not want to say that we can know heavy-weight assumptions, even if these are entailed by ordinary empirical propositions we know. His way out of this impasse consists in claiming that our attitude towards these assumptions is not one of belief and that we would never acquire such a belief because of an application of the Closure principle. Since belief is necessary for knowledge, it follows that the Closure principle is simply not applicable in those cases in which the consequent of the known conditional is a "heavy-weight" proposition, or, as Pritchard prefers to call it, a "hinge commitment".

Now, it is important to note, first, that obsessing over the unrestricted validity of Closure is motivated only to the extent that Closure itself is seen as a generative principle. That is, as a principle which allows us to extend our justification (or knowledge) from the premises of a given argument, to its conclusions, via known entailment. This, however, is not a sacrosanct reading of it. In fact, since at least Wright (1985), it has become customary to distinguish between Closure and Transmission of justification (or other epistemic operators, such as warrant, knowledge and later on, entitlement). In my own work, I have explained the difference by saying that all it matters to Closure is that the same kind of epistemic operator would figure in the premises and the conclusion of the argument, irrespective of the provenance of the relevant epistemic good. Thus, for instance, if one were justified in believing that $\mathrm{Q}$ through testimony, and one were justified in believing that $\mathrm{P}$ through perception, and were justified a priori to believe that $\mathrm{P}$ entails $\mathrm{Q}$, Closure for justification would be respected and yet it would not thereby give one a first justification to believe Q; nor would it enhance any antecedent justification one would have for Q already. Transmission, in contrast, would be the generative principle that would either give one a first justification to believe Q, or enhance one's antecedent justification for it. ${ }^{8}$

\footnotetext{
6 I myself have defended this strategy in Coliva (2015, chapter 3). Dretske (1970) and Nozick (1981) have too, although they differed about the principled reasons why Closure should fail. Their reasons were grounded in their respective accounts of knowledge. Mine are in fact grounded in a "moderate" conception of the structure of empirical justification, according to which the latter is due to having a certain course of experience, absent defeaters, once certain heavyweight assumptions-like "there is an external world", or "our sense organs are mostly reliable", etc.—are in place.

7 See Coliva (2015, chapter 3).

8 Notice, moreover, that in Coliva (2015, chapter 3), I have proposed a more nuanced account of Transmission of justification principle (and of its failure) than Wright's. In my opinion, there are two kinds of it. Namely, Wright's, which imposes that for an argument to transmit justification (or warrant, in his terminology) from the premises to the conclusion, justification for the latter is not needed in order to have justification for the former; and another one, call it Coliva's, that imposes that for an argument to transmit justification (or warrant) from the premises to the conclusion, the latter need not be assumed in order to have justification for the former. I have argued that while these two kinds of transmission are compatible
} 
While this is important, I think, to differentiate various epistemic principles, which may be more or less significant to us and thus difficult to abandon, the choice of calling "Closure" what others would call "Transmission" is ultimately terminological. So, let us grant Pritchard his own reading of Closure-which makes it a case of transmission by other epistemologists' lights - and let us turn to a discussion of his way out of the impasse.

One way Pritchard could go would be to say, with Wittgenstein, that since hinges are rules and rules are not propositions, they are not apt to be contents of beliefs and knowledge. Yet, Pritchard does not want to take this route-and rightly so in my opinion. For it is difficult to motivate the idea that hinges have no descriptive content, even though they may, in context at least, play a normative role. Moreover, they can clearly figure as antecedents in conditional statements, they would admit of meaningful negations and could occur in disquotational schemas. Of course, perceptive supporters of the non-propositional reading of hinges are aware of all that and typically claim that in all these cases we would have the same sentence-a doppelgänger of the hinge—-playing no hinge role, though. ${ }^{9}$ This defense, however, is problematic on multiple fronts. For instance, it would entail some kind of semantic ignorance on our part, since we would typically be oblivious to such a difference. It would also not fit well with at least some of Wittgenstein's own remarks on On Certainty, in which he contends that the very same proposition can be treated as a rule of testing and as something to be tested, depending on occasion (cf. OC 96-99).

As noticed, Pritchard's solution is to retain the propositionality of hinges while making them the content of a peculiar attitude, different from belief, called "commitment". Now, one may legitimately wonder what commitments are. Yet, Pritchard is surprisingly silent on how exactly we should understand them. To be reminded, in a Wittgensteinian spirit, that commitments encode the idea that we bear to hinges a kind of animal, visceral certainty is fine as far as it goes, but it should not obscure the fact that we can and do conceptualize hinges and that they are the content of some kind of propositional attitude after all. Indeed, this seems to be a straightforward consequence of Pritchard's rejection of the non-propositional reading of hinges. Yet, if hinges are propositions and are the content of a specific attitude, then it is the very attitude at play that is doing all the philosophical work. Thus, the question remains as to what commitments really amount to.

True, we are told that they are a kind of propositional attitude, and that they are different from beliefs. Now, other hinge epistemologists (see Wright 2004; Coliva 2015), have labored to develop a notion of acceptance, which is not based on evidence in favor of the proposition that constitutes it content. Acceptance, in turn, is a propositional attitude in which the subject takes or holds the propositional content to be true. ${ }^{10}$ It is

\section{Footnote 8 continued}

with one another, as they apply to different kinds of argument, the philosophically more interesting one is in fact the latter.

9 See Moyal-Sharrock (2005, pp. 140-143). For a critical appraisal, see Coliva (2010, pp. 152-161). 
not clear in what way, if any, Pritchard's notion of commitment is any different from what other hinge epistemologists call "acceptance".

According to Pritchard, this move would block the usual objections to deniers of Closure because Closure holds only for belief and thus it does not apply to commitments. As simple as the proposal looks like, I am not entirely convinced it would work. For, if "There is an external world" is a proposition and, as Pritchard holds, it is knowledgeably entailed by "Here is a hand", how come that we can know that we have a hand and yet not know that there is an external world? In fact, how come that we can know we have a hand and yet not even be allowed to form a belief with respect to "There is an external world", which is a proposition we know to be entailed by "Here is a hand"? Merely insisting that it is a commitment would sound ad hoc. One way to bring out the worry is to consider the following. I would grant Pritchard that we do not typically come to hold that there is an external world by going through an inference such as the previous one. That inference, that is, is not generative of knowledge. But why cannot it at least generate belief, ex post, if it is a valid inference, by Pritchard's lights? The problem is similar to the one usually raised against other hinge epistemologies, and known by the name of "alchemy". ${ }^{11}$ Suppose you have a hinge commitment in "There is an external world", acquired one way or another (Pritchard does not say how), which allows you to have a justified belief (or even knowledge) that there is your hand where you see it. Now, consider realizing that "Here is a hand" entails "There is an external world". Why shouldn't this inference allow you to bolster your initial commitment in "There is an external world" and turn it into a belief (or even into a justified, or knowledgeable belief)? The answer is not clear and more would need to be said.

Similarly, it would help to be more explicit about how the proposal fares with respect to the charge of licensing "abominable conjunctions" such as "I know I have a hand but I don't know there is an external world". ${ }^{12}$ My hunch is that, in the end, Pritchard will have to concur with other hinge epistemologists that the scope of the Closure principle is limited to known entailments flagging ordinary empirical propositions on both sides of the conditional, or, more generally, propositions which are not hinges and can therefore be known and consequently (justifiably) believed. Furthermore, it is my hunch that in response to the charge of licensing abominable conjunctions, Pritchard would have to say, with other hinge epistemologists that the charge is ultimately based on not realizing a crucial, yet very subtle difference (see Harman and Sherman 2011), between belief and commitment, however Pritchard may want to spell out the latter notion. Once that crucial difference is appreciated, then the initial conjunctions will have to be substituted with something like the following "I know I have a hand, and I don't know that there is an external world, yet the latter is a hinge commitment of mine". Furthermore, since officially Pritchard's story has it that this in an a-rational commitment, he might have to say something more to minimize the effect of adding that specification in the relevant conjunct. For instance, he might point out how, even

\footnotetext{
10 Wright thinks it involves a form of trust in which one is taking a risk. I do not think this is a necessary component of acceptance and I believe Wright's reading is at odds with On Certainty. See Coliva (2010, pp. 135-138).

11 See McGlynn (2012). (Cf. fn. 5).

12 See DeRose (1995).
} 
though a-rational, that commitment is in fact necessary for the acquisition of justified belief and eventually knowledge of the ordinary empirical proposition that figures in the other conjunct. ${ }^{13}$

Thus, I do think Pritchard would have available to him various responses to the objections usually raised against people who deny the unrestricted validity of Closure, which will in turn have to be assessed on merit. Yet it is crucial that the very notion on which they would hinge-pun intended-namely, the notion of hinge commitment, be spelled out in more detail.

\section{On Certainty and underdetermination-based skepticism}

The other issue I would like to consider is whether it is really the case that Wittgenstein's remarks in On Certainty do not provide us with any useful element to counter Underdetermination-based skepticism. Pritchard painstakingly discusses this form of skeptical paradox. Here I will just offer a broad-brush characterization of it. If you hold that it is possible for a subject to have the same kind of evidence irrespective of whether she is actually perceiving a hand in front of her, or whether she is merely hallucinating having one, it follows that, whatever is rationally available to a subject actually falls short of providing her with knowledge of (or justified belief in) "Here is my hand". Now, Wittgenstein's own insistence on the locality of reasons is matched by the idea that knowledge and justification do take place. Yet, they are not direct or immediate, since they take place within a system of assumptions (or hinge commitments, if you will). The latter are not themselves known or justified, yet stand fast for all of us and actually allow us to form justified beliefs and to gain knowledge of (among others) ordinary empirical propositions about mid-size physical objects. Hence, on this reading of Wittgenstein's remarks in On Certainty, he would not be rejecting the idea that perceptual experiences are in principle indistinguishable whatever their causal origin might be. Yet, he would offer us considerations in favor of the idea that these experiences take place within a system of hinges, which are actually unassailable by skeptical attacks, and that allow us to acquire justification and knowledge about physical objects in our surroundings. In other words, once one is willing, as Pritchard is, to buy into the idea of hinges, which are impervious to skeptical assaults, then there seem to be enough elements in Wittgenstein's On Certainty to counter Underdetermination-based skepticism too. Let me clarify how: by means of hinges such as "There is an external world" and "Our senses are broadly reliable", by having a hand-like experience, absent defeaters, one would thereby possess a justification for "Here is a hand". That is, thanks to the hinge, one would be entitled to take one's perceptual experience at face value as favoring "Here is a hand" (as opposed to its skeptical counterpart, e.g. "I am a handless BIV hallucinating having a hand").

\footnotetext{
13 In my opinion, it is not wise to insist on the "a-rationality" of commitments. For that idea is completely in line with skepticism about hinges. In my own work, I have labored to distinguish between the fact that we do not possess evidence (or other forms of justification) for hinges and the fact that they would thereby fail at rationality altogether, through the notion of extended rationality. Accordingly, epistemic rationality extends beyond evidentially justified beliefs to those assumptions which, while unjustifiable, make the acquisition of epistemic justifications possible in the first place.
} 
Thus, there is a sense in which, thanks to hinges, our perceptual experiences provide us with a better rational support than their subjectively indistinguishable skeptical counterparts, such as BIV-experiences. That is, thanks to hinges, they provide us with "decisive" reasons in favor of the corresponding ordinary empirical propositions. ${ }^{14}$

Furthermore, on this picture, one can actually offer one's perceptions as reasons in support of one's claim that, say, there is a robin on a tree one is looking at. For, given one's available evidence and the suitable hinges, one can trust one's senses, absent defeaters, and justifiably believe that there is a robin on a tree in virtue of one's current perceptions. Hence, I am not sure why Pritchard thinks we should turn to disjunctivism to solve the Underdetermination-based skeptical paradox. ${ }^{15}$

Still, let us assume for the sake of the argument that one needs to supplement Wittgenstein's position considerably in order to confront that paradox. The question now is whether epistemological disjunctivism would really help. Surely, epistemological disjunctivism can easily explain the commonsensical intuition that we justify our beliefs regarding specific physical objects in our surroundings by saying "Because I see that such-and-so". As we saw, however, a Wittgenstein-inspired view would be equally well placed to explain that intuition. Moreover, it would be equally well placed to account for the intuition that our perceptual experiences would give us a better rational support to believe ordinary empirical propositions rather than their skeptical counterparts, thanks to the relevant hinges. Hence, those considerations are not enough to motivate the endorsement of disjunctivism.

Pritchard then claims that when one is actually seeing a robin on a tree, say, one would be able to favor the good-case scenario over a bad one by appealing to further considerations regarding the absence of defeaters. So one would be able to favor the former scenario even if one could not perceptually tell the difference between the two cases. ${ }^{16}$ While we should happily grant all that, these further considerations, as Pritchard notices, would be impotent to help one dismiss a radically skeptical scenario, like the Cartesian one, since they would be compatible with the obtaining of it. Hence, according to Pritchard, we should remember that radically skeptical hypotheses are "by their nature bare - that is, rationally unmotivated-error possibilities" (p. 140), to which we can respond just by appealing to the fact that we are seeing a robin on a tree. Still, we cannot thereby conclude that we know the denial of radically antiskeptical hypotheses. Here-I take it-is where Wittgenstein's considerations become germane again, for it is only by reverting to them that radically skeptical scenarios can be dismissed and yet we do not reach a position where we can actually know their denial.

The worry, however, is that responding this way to the Underdetermination-based skeptical paradox is dialectically suspicious. For either there is no such radically skeptical paradox at all, and the problem is merely one of vindicating the idea that we can use perceptions to justify (or claim knowledge of) our ordinary empirical beliefs. Or else, there is a radically skeptical paradox, which is different from its Closure-

\footnotetext{
14 Cunnigham (2016) uses the adjective "decisive".

15 For another account sympathetic to Wittgenstein's position in On Certainty, and skeptical of the need of complementing it with disjunctivism, see Ashton (2015).

16 For a critical appraisal of Pritchard's disjunctivism, see Ranalli (2018). For the relationship between Pritchard's epistemological disjunctivism and metaphysical disjunctivism, see Cunningham (2016).
} 
based counterpart, and that crucially depends on the indistinguishability thesis. If the former is the case, disjunctivism is right to respond that we may appeal to various considerations concerning the absence of real (as opposed to purely skeptical) defeaters to favor a good-case scenario, even if it is subjectively indistinguishable from a badcase one. Yet, as we saw, a Wittgenstein-inspired response would be equally well placed.

In the latter case, in contrast, I am not sure, first, that Pritchard has really differentiated the Underdetermination-based paradox from the Closure-based one. After all, he seems to be saying that what needs to be shown is how we can dismiss radical skepticism about hinges, once we realize we cannot acquire or vindicate knowledge of those through an inference, such as a Moorean one, which starts out with the knowledgeable premise "Here is a hand" and allegedly derives the knowledgeable conclusion that there is an external world. That paradox looks to me identical to the Closure-based one. Second, whether or not the Underdetermination-based paradox really differs from the Closure-based one, it remains that it cannot be dispelled by appealing to further considerations regarding the absence of real defeaters, and disjunctivism turns out to be unable to respond to it. Rather, all the anti-skeptical work seems to be done by Wittgenstein-inspired considerations regarding the dubiously rational status of skeptical hypotheses. For it is part of that work that only motivated doubts, which have consequences in practice and that can be resolved at least in principle, are rational. (cf. OC 154, 231, 255, 256, 339). That entails that hinges have to stay put (cf. OC 160-162, $310-318,327,505,522-523)$. Yet, once they are in place, they ground our justification for, or even knowledge of, ordinary empirical propositions. If so, however, embracing disjunctivism would not represent any clear advantage over an account of perceptual justification, and knowledge, more in keeping with Wittgenstein's own views in $O n$ Certainty.

One might then appeal to a more traditional variant of disjunctivism, which incorporates the claim Pritchard is uncommittal about that perceptions and delusionary experiences are metaphysically distinct mental states. By so doing, one may hold that, in the good case, when one does perceive, one knows that there is a robin on a tree, while in the bad case one doesn't. One might then hold that, in the good case, one would thereby also know that one is not a BIV, even if one is unable to tell how one knows. Yet, it should be noted that this move would sever the desirable connection between knowledge and its rational availability to a subject Pritchard is concerned to maintain. Alternatively, one might deny the entailment between one's knowing that there is a robin, when one is in the good case scenario, simply on the basis of one's perception, and knowing that one is not a BIV. This move, however, would be based on a rejection of the unrestricted validity of Closure, which again, as we saw in the previous section, is something Pritchard aims to avoid.

Let us take stock. I have argued that disjunctivism per se - especially in the internalist more friendly version favored by Pritchard-does not have any advantage over Wittgenstein's own position in On Certainty, because the latter too can accommodate the fact that we give (and have) perceptually-based reasons for our claims to knowledgeable or justified belief for ordinary empirical propositions, rather than for their skeptical counterparts. Furthermore, it is in On Certainty that we find the means to dismiss the rational status of radically skeptical scenarios, like the ones exploited in the 
Closure-based version of the skeptical paradox as well as in its Underdeterminationbased counterpart. In particular, and to reiterate, it is part of On Certainty that only motivated doubts, which have consequences in practice and that are at least in principle resolvable, are rational. For those rational doubts to be possible, however, hinges have to stay put. Connectedly, thanks to the fact that hinges stand fast for us, we can have, and can claim to have perceptually-based (or even testimonial) justifications for our empirical beliefs. Thus, I think it is safe to say that turning to disjunctivism to supplement On Certainty, since the latter would allegedly be defective in its own right, is a moot move.

\section{Disjunctivist perception?}

In closing, I would like to consider another worry that disjunctivism raises independently of its possible interplay with ideas to be found in On Certainty. Namely, the account of perception it provides. This is an issue that Pritchard himself, in keeping with other mainstream epistemologists, does not consider, for it traditionally falls in the remit of the philosophy of mind. Yet, boundaries need to be crossed to provide theories, which, while prime facie plausible in one realm, would actually falter if considered from a different, wider perspective. This is precisely the case with disjunctivism, which, while at least prima facie plausible if considered merely from an epistemological point of view, does not do equally well when apprised from the point of view of the philosophy of perception. Here I will not have the space to develop the point in any detail. Yet, it is generally agreed upon that if we look at cognitive psychology, and take vision as our leading example, it turns out to provide representations of distal stimuli according to complex (subpersonal) algorithms, which cognitive scientists investigate. The information processing is subpersonal (and indeed the algorithms just model it). Still, the resulting representational state is a person-level mental state, either because it often involves consciousness, or else because, even when it does not, it drives purposive behavior. Proximal stimuli, however, under-determine the distal conditions that cause them. Thus, the resulting representations are never a direct taking in of what caused them, not even in the veridical case. Moreover, the same kind of representations can be produced by stimulating the relevant areas in the brain by means of electrodes. Thus, visual representations as such are insensitive to their causes, and reference to the latter is needed to distinguish between veridical and illusionary (or even hallucinatory) ones. In other words, visual perceptions and hallucinations are not two different kinds of mental state, as they do have a "highest common factor", ${ }^{17}$ generated through two different causal chains.

Were one to insist that, nevertheless, they are two different kinds of mental state because their individuation should be wide and take into account the relevant causes, one could then object that the wider individuation seems to be entirely ad hoc, and that are plenty of good reasons to do otherwise. In particular, the narrower individuation seems to account better for the fact that, assuming that at least in some cases perception

17 Pace McDowell (1982). 
and hallucination provide a similar (or even identical) representation, that would lead subjects to act in similar (or identical) ways, ceteris paribus.

Moreover, in perceptual psychology, which is the most developed psychological science, "factive-type states are less fundamental". ${ }^{18}$ That is, "explanations in psychology center on kinds of psychological states that do not entail veridicality". ${ }^{19}$ Furthermore, these psychological states, even when they are veridical, are representations of objects and properties out there (and are representations as of those objects and properties). Yet, they should not be conflated with their representata. Contrary to McDowell-style disjunctivism, therefore, contemporary perceptual psychology does not allow for the possibility of taking in facts - understood as properly arranged combinations of objects and properties, or even relations - through perception. ${ }^{20}$ Thus, in keeping with our best science of perception, there seem to be very little reason for going disjunctivist.

True, as previously remarked, Pritchard is uncommittal about the metaphysical status of perceptions and hallucinations. Yet, as we have all too briefly remarked, there are good reasons not to follow other, more traditional disjunctivists ${ }^{21}$ on that score. If so, however, it is unclear what the supposed advantages of disjunctivism over the view of perceptual justification elicited from On Certainty would be. For one could not insist, at this point, that, if all goes well and we are in fact perceiving that $P$, then we are immediately in touch with the corresponding fact in the world and, provided we are capable of forming the corresponding belief, we thereby have direct knowledge of it. Thus, one important anti-skeptical move traditional disjunctivists would be able to make, would no longer be available. ${ }^{22}$

As we have seen, moreover, there are good reasons to hold that disjunctivism per se is impotent against the Underdetermintion-based version of the skeptical paradox and that it is not, as such, particularly better placed, vis-à-vis Wittgenstein's own views in On Certainty, to vindicate the intuition that perception provides us with reasons in favor of our claims to knowledge or justified belief. Thus, I confess, I ultimately see no reason for contaminating hinge epistemology with it. Yet, it remains that the attempt is bold and interesting. Thus, it certainly deserves full consideration and further discussion.

\section{References}

Ashton, N. (2015). Undercutting underdetermination-based scepticism. Theoria, 81, 333-354.

Burge, T. (2010). Origins of objectivity. Oxford: Oxford University Press.

Coliva, A. (2010). Moore and Wittgenstein. Scepticism, certainty and common sense. London: Palgrave.

18 Burge (2010, p. 62, fn.1).

19 Ibid. Cf. also Burge (2010, p. 362-364, fn. 97; and pp. 392-394).

20 See Burge (2010, p. 84, fn. 33).

21 Cf. McDowell (1982).

22 This is not to say that that move would be ultimately successful. For one could still raise a second-order skeptical paradox, according to which it may be conceded that one has knowledge that there is a hand if one is perceiving one's hand. Yet, the issue would then be how one could claim to have that knowledge, or rationally redeem it, if the possibility that perceptions and hallucinations may be subjectively indistinguishable is granted. For this line of argument against McDowell, see Wright (2002). 
Coliva, A. (2015). Extended rationality. A hinge epistemology. London: Palgrave.

Coliva, A., \& Moyal-Sharrock, D. (Eds.). (2016). Hinge epistemology. Leiden: Brill.

Cunningham, J. J. (2016). Reflective epistemological disjunctivism. Episteme, 13(1), 111-132.

DeRose, K. (1995). Solving the skeptical problem. Philosophical Review, 104(1), 1-52.

Dretske, F. (1970). Epistemic operators. Journal of Philosophy, 67, 1007-1023.

Harman, G., \& Sherman, B. (2011). Knowledge and assumptions. Philosophical Studies, 156(1), 131-140.

McDowell, J. (1982). Criteria, defeasibility and knowledge. Proceedings of the British Academy, 68, $455-479$.

McGlynn, A. (2012). On epistemic alchemy. In D. Dodd \& E. Zardini (Eds.), Scepticism and perceptual justification (pp. 173-189). Oxford: Oxford University Press.

Moyal-Sharrock, D. (2005). Understanding Wittgenstein's On Certainty. London: Palgrave.

Nozick, R. (1981). Philosophical explanations. Cambridge (Mass.): Harvard University Press.

Pritchard, D. (2016). Epistemic Angst. Radical skepticism and the groundlessness of our believing. Princeton: Princeton University Press.

Ranalli, C. (2018) Epistemological disjunctivism and introspective indiscriminability. Philosophia 1-22.

Strawson, P. (1985). Skepticism and naturalism. Some varieties. New York: Columbia University Press.

Williams, M. (1991). Unnatural doubts. Oxford: Blackwell.

Wittgenstein, L. (1969). On Certainty. Oxford: Blackwell.

Wright, C. (1985). Facts and certainty. Proceedings of the British Academy, 71, 429-472.

Wright, C. (2002). (Anti-) sceptics simple and subtle. G. E. Moore and John McDowell. Philosophy and Phenomenological Research, 65, 330-348.

Wright, C. (2004). Warrant for nothing (and foundations for free)? The Supplementary Volume of the Aristotelian Society, 78, 167-212.

Wright, C. (2012). On epistemic entitlement (II): Welfare state epistemology. In D. Dodd \& E. Zardini (Eds.), Scepticism and perceptual justification (pp. 213-247). Oxford: Oxford University Press. 